\title{
Impact of secondary roads on wildlife of coastal center region Portugal and differences between before and post fire.
}

Tiago Miguel Regateiro Cruz ( $\sim$ tiago_cruz5@hotmail.com )

Universidade de Aveiro Departamento de Ciencias Sociais Politicas e do Territorio

https://orcid.org/0000-0002-1734-9108

Joana Lima

Universidade de Aveiro Centro de Estudos do Ambiente e do Mar

António Luis

Universidade de Aveiro Centro de Estudos do Ambiente e do Mar

Ulisses Miranda Azeiteiro

Universidade de Aveiro Centro de Estudos do Ambiente e do Mar

Research article

Keywords: Agriculture area, Fire, Forest area, Impact, Portugal, Roads, Wildlife

Posted Date: October 9th, 2019

DOI: https://doi.org/10.21203/rs.2.15714/v1

License: (9) This work is licensed under a Creative Commons Attribution 4.0 International License.

Read Full License 


\section{Abstract}

Background Anthropogenic activities affect ecosystems creating stress and new disturbances. Among these anthropogenic activities, we highlight roads that are main cause of habitat segmentation. As roads were built to accommodate traffic in rural areas, rate of vehicle-wildlife collisions has significantly expanded, thereby causing a direct decrease in population size. This study was conducted in Portugal (country's western central coast) and assessed impact of secondary roads on wildlife, as well as the influence that a catastrophic event, like a great fire, has on this wildlife. Practical work was carried out during 15 months (from October 2016 to December 2017), two consecutive days per week, first day being used for "road cleaning", that is, collection of all animals found on road, followed of their identification, and second day for morning and afternoon collection and identification of dead animals found on same tracks.

Results In Agricultural Zone, vertebrate deaths on the road covered 17 species. Birds were the most affected, followed by amphibians, mammals and reptiles. The most fragile species were Passer domesticus and Salamandra salamandra. Two hotspots were recognized, one on each road. In Forestral Zone, vertebrate deaths on road included 26 species. Mammals were most vulnerable in this area followed by birds, amphibians and reptiles. Bufo bufo and Salamandra salamandra were the most vulnerable species. On the contrary, differences between roads composition were clear: there were only deaths on asphalted roads. Differences between before and after fire are evident

Conclusions In this study, it was concluded that different zones and therefore different habitats should be worked on separately and that mitigation measures should be implemented as a priority in so-called "hotspots". This work highlights importance of secondary roads as a source of mortality for wildlife, and these should not be ignored. As far as macadam roads are concerned, they are not a threat to vertebrate populations in municipality of Mira. In future, it would be important to improve this work by including volume of traffic on roads and recording kilometers at which animals were collected. Results before and after fire illustrate the impact of this catastrophic event on wildlife.

\section{Introduction}

Roads are a critical component in civilizations. Development of economic activity, which is vital to quality of modern life, would be difficult without roads. They play a central role in urban and economic development (Forman et al., 2003).

Construction and maintenance of roads became controversial because of their effects on environment. Many roads become barriers to wildlife. On the other hand, road networks may include extensive road borders that serve as habitats, as well as viaducts, bridges, coverages and pipes that can facilitate and channel water and species movements (Forman et al., 2003).

Animals can be attracted by roads for a variety of reasons, but mostly related to habitat, ease of movement and food resources (Forman et al., 2003). In a study by Meunier et al. (2000), birds of prey 
used road berms more than adjacent habitat, not by the abundance of prey but by the greater availability of perches.

Among anthropogenic activities, construction of transportation infrastructures, considered deforestation agents, is the main cause of habitat fragmentation (Young, 1994, Laurance et al. 2002, Geneletti, 2004, Liu et al. 2008).

Landscape connectivity is the degree to which landscape facilitates animal movement and other ecological flows, allowing many multi-habitat organisms to move regularly through landscape to different habitat types in order to meet their daily and living needs (Jonsen and Taylor, 2000, Pope et al.., 2000, Forman et al.,, 2003). Barriers that prevent these movements, such as roads, result in higher mortalities, lower reproduction rates, and, ultimately, lower viability of populations (Forman et al.,, 2003). A recent study in Germany showed genetic effect of different roadblocks, using populations of blind rat (Clethrionomys glareolus) as object of study. The authors found a significant genetic subdivision of populations separated by a highway, but not within populations separated by a national road or railroad (Gerlach and Musolf, 2000, Forman et al.,, 2003).

As roads were built to accommodate large traffic densities in rural areas, rate of vehicle-wildlife collisions has increased significantly (Forman et al.,, 2003, Grilo et al.,, 2009), causing a direct reduction in population size. If such effects are strong enough, the road will may become a deposit of populations, contributing to local extinction of species (Woodroffe and Ginsberg, 1998).

Fire

Occurrence of a Fire has a number of effects that occur both in the burned area and nearby areas. The extent of these effects depends on intensity of Fire which, in turn, depends on meteorological factors, fuel burned and terrain slope (Harper et al.,, 2016).

The most drastic effect that a plant community can suffer after a fire is death of all plants. In plant community there're almost always species that bloom again after a fire. On the other hand, not always a fire reach tree tops and, when that happens, damages could not imply their vital functions ceasing (Butler et al.,, 2010).

In general, indirect effects of fire on animal populations that depend on a particular plant community, which suddenly ceases to exist, are far more important than mortality directly caused by fire (Turne et al. 1999, Perry et al. 2011, Crotteau et al. 2013). In relation to fauna of soil, it is generally verified a significant decrease of populations of different species that inhabit the more superficial layers of soil and dead blanket. Other groups of insects, such as ants, may, on contrary, see an increase in diversity of species, due to ability of them to colonize new environment. It is also this ability to colonize a new environment that leads to increase of some forest pests (Engstrom et al.,, 2010, Hutto, 2008).

In relation to mammals, effects of a fire can also vary, depending greatly on intensity of fire and area burned. In high-intensity and large-scale fires, effects may be highly negative on these species, given the 
sudden absence of shelter and feeding. This type of effect is much more important than direct mortality, since a large proportion of animals can escape the flames or take refuge in burrows below surface (Engstrom et al.,, 2010).

In summary, we can say that, effects of fires at ecosystems level are very important, since they constitute a sharp break in the various cycles and chains of which are part. Although fire is an integral part of natural cycle of Mediterranean regions, recovery after a fire can take a long time, especially if affected systems are result of many years of evolution. In any case, this depends on affected system, and an oak forest inevitably will take much longer to recover than a pasture or low-lying scrub (Dickinson et al.,, 2010). How frequency of fires is now much higher than was naturally occurring, their effects will, as such, become more serious as long as it is necessary to restore previous situation.

Thus, in this work, we wanted to answer the following questions:

- What is the impact of secondary roads on wildlife?

- Is there a difference between agricultural and forestry roads?

- Is there a difference between tarmac and macadam roads?

(iv) What are the most affected species or taxonomic groups?

(v) Will be the impact related to temporal and spatial factors (times of year, day / night, forest zone / agricultural area)?

(vi) Is there a significant difference in the number of deaths and in the most affected classes after the fire?

\section{Materials And Methods}

\section{Study area}

Municipality of Mira is located in central coastal region of Portugal. In central and eastern part of municipality, road network is quite dense and branched, establishing contact between villages. The western part of municipality, except Praia de Mira and surrounding area, has a network of low-density roads. There are some important secondary roads: Via Sul and Via Norte, which result from enlargement and paving of old forest roads that cross Forest and Dunes of Mira (Petronilho, 2001).

As for climate, summers are moderately warm and winters mild. The annual average temperature is $14.3^{\circ} \mathrm{C}$ and annual precipitation is $1002.8 \mathrm{~mm}$. Throughout the year, winds blow more often from North and West, with predominance of North. The area covered by municipality belongs to Meso Mediterranean bioclimatic zone (Petronilho, 2001). In the municipality of Mira there are six habitat types: sandy beaches and coastal dunes, forested areas, wetlands, agricultural areas, inhabited areas and bush areas (Petronilho, 2001). In this article, only those related to the study are described. 
Today the forestry perimeter of dunes and pinewoods of Mira area is associated with fauna that includes the common toad (Bufo bufo)," western spadefoot (Pelobates cultripes)," natterjack toad (Bufo calamita)," fire salamander (Salamandra salamandra)," slow worm (Anguis fragilis), ocellated lizard (Lacerta lepida), large psammodromus (Psammodromus algirus), Montpellier snake (Malpolon monspessulanus)," southern smooth snake (Coronella girondica)", red fox (Vulpes vulpes)," common genet (Genetta genetta), wild boar (Sus scrofa)," wood-mouse (Apodemus sy/vaticus),, european rabbit (Oryctolagus cuniculus)," greater white-toothed shrew (Crocidura russula), common buzzard (Buteo buteo),, northern goshawk (Accipiter gentilis),, Eurasian sparrowhawk (Accipiter nisus),, black kite (Milvus migrans),, European turtle dove (Streptopelia turtur),, common wood pigeon (Columba palumbus),, common cuckoo (Cuculus canorus),, tawny owl (Strix aluco),, northern long-eared owl (Asio otus)," European nightjar (Caprimulgus europaeus)," great spotted woodpecker (Dendrocopos major), Eurasian jay (Garrulus glandarius)," common firecrest (Regulus ignicapillus)," European pied flycatcher (Ficedula hypoleuca), European robin (Erithacus rubecula)," European blackbird (Turdus merula),, mistle thrush (Turdus viscivorus),, coal tit (Parus ater), European crested tit (Parus cristatus),, great tit (Parus major),, long-tailded tit (Aegithalos caudatus),, Eurasian nuthatch (Sitta europaea), common chaffinch (Fringilla coelebs),, hawfinch (Coccothraustes coccothraustes),, serin (Serinus serinus),, wren (Troglodytes troglodytes),, garden warbler (Sy/via borin) and spotless starling (Sturnus unicolor) (Petronilho, 2001).

In county agricultural lands associated fauna includes: common toad (Bufo bufo),, Montpellier snake (Malpolon monspessulanus),, psammodromus lizard (Psammodromus algirus), woodland mouse (Apodemus sylvaticus),, greater white-toothed shrew (Crocidura russula), common rabbit (Oryctolagus cuniculus), "Granada hare (Lepus granatensis), , red fox (Vulpes vulpes)," common mole (Talpa caeca)," weasel (Mustela nivalis),, cattle egret (Bubulcus ibis)," common buzzard (Buteo buteo),, black-winged kite (Elanus caeruleus),, kestrel (Falco tinnunculus)," quail (Coturnix coturnix),, European turtle dove (Streptopelia turtur),, barn owl (Tyto alba), European nightjar (Caprimulgus europaeus),, european roller (Coracias garrulus)," greater short-toed lark (Calandrella brachydactyla),, cresyed lark (Galerida cristata), barn swallow (Hirundo rustica),, spotless starling (Sturnus unicolor),, magpie (Pica pica),, carrion crow (Corvus corone), blackbird (Turdus merula), sparrow (Passer domesticus),, serin (Serinus serinus)," goldfinch (Carduelis carduelis),, and cirl bunting (Emberiza cirlus) (Petronilho, 2001).

\section{October 2017 Portugal wildfires}

At least 45 people died after hundreds of fires spread across central and northern areas on Sunday (15th) and Monday (16th). They started in dry conditions and were fanned by strong Atlantic winds from Hurricane Ophelia. They spread quickly at weekend across a landscape left tinder dry by hot summer. Latest data from European forest fire information system, EFFIS, indicate that area burnt in Portugal in 2017 is already over 500,000 hectares. A researcher at Higher Institute of Agronomies admits in statements to Observador (2017) newspaper that only on Sunday will have burned between 120,000 and 150,000 hectares. Cardoso Pereira adds that fire burned more in one day than annual average burned area - one hundred thousand hectares. Sunday also stay to history of fires, as the day with largest area 
burned in 24 hours, when in the great fires of August 50 thousand hectares per day were burn. Mira county has recorded a burned area of 70\% (Jornal de Noticias, 2017) (figure. 1).

\section{Fieldwork}

Practical work was carried out during 15 months (from October 2016 to December 2017), two consecutive days per week, first day being used for "road cleaning", that is, collection of all animals found on road, followed of their identification, and second day for morning and afternoon collection and identification of dead animals found on same tracks.

Cleaning of forest roads was done twice a month (approximately every 15 days), interspersed weekly with cleaning of agricultural roads. On day after each of these roads clean, a new collection was carried out, this time in the morning (7:30 am), to calculate number of individuals killed during night, and afternoon $(6: 30 \mathrm{pm})$ in order to evaluate number of individuals killed during day.

Were created 12 transects ( 8 forest and 4 agricultural) with $3 \mathrm{~km}$ long, each one. Transects are located in Forest Perimeter of Dunes and Pinewood of Mira and in Mira agricultural area. The 12 transects constitute 6 roads (two transects of $3 \mathrm{~km}$ in each road) (figure 2).

The unidirectional visit was performed, on each transect, using a bicycle at a speed of about $10 \mathrm{~km}$ per hour ("walking speed") in order to be able to observe animals carefully, thus adopting reduced speeds as in works by Marques (1994) and Petronilho and Dias (2005). We done animals identification according to identification guides of amphibians and reptiles of Nuno Ferrand de Almeida, Paulo Ferrand de Almeida, Helena Gonçalves, Fernando Sequeira, José Teixeira and Francisco Ferrand de Almeida (Guia FAPAS Amphibians and Reptiles of Portugal), birds of Bertel Bruun, Håkan Delin and Lars Svensson (Guia FAPAS - Birds of Portugal and Europe) and mammals of David MacDonald and Priscilla Barret (Guia FAPAS Mammals of Portugal and Europe). Animals that were not possible to identify due to animal deformity were considered unidentified. After each identification, animals were removed from road. The impact of fire was observed by recording post-fire animal deaths and by comparison with pre-fire records.

Roads have a steady traffic volume of approximately 200 vehicles per day on tarmac roads and 20 on macadam roads with a small increase on weekends and in the summer and so this work was done during the week. Traffic also remained constant before and after the fire.

\section{Statistical analysis of data}

Data collected were then processed through statistical analysis to determine average number of road accidents per year on forest and agricultural roads; compare these numbers with time of year and with taxonomic groups most affected by this fatality; compare roads impact during day and night, assess impact of different roads on wildlife, and finally verify influence that a large-scale fire has on deaths by classes and number of individuals per species, safeguarding constitution and structure of each road (asphalt or macadam). 
Therefore, non-parametric Mann Whitney hypothesis test was carried out in order to verify if the two zones (agricultural and forestry) had significant differences between them and if, therefore, they could be analyzed separately. Analyzed variables were total number of road deaths ("Deaths"), number of deaths during day and night ("Day / Night"), number of deaths of amphibians ("Amphibians"), number of bird deaths ("Birds"), number of deaths of mammals ("Mammals"), number of deaths of reptiles ("Reptiles"), number of deaths during winter ("Winter"), number of deaths during spring ("Spring") and number of deaths during the summer ("Summer") number of deaths before and after a fire ("Before / After").

After results of first analysis, two zones were worked separately but subject to same tests (except analysis for type of road surface that was only made for forest area). To determine number of deaths/km/year in each zone, average number of deaths per week was calculated and multiplied by number of weeks of one year per kilometer. Then, in order to verify variance of deaths during studied months of year and to analyze if differences between seasons of year would be significant, a graph followed by an ANOVA variance analysis was constructed.

To find out which taxonomic group most affected in each zone, a graph was drawn in Excel. Determination of differences between road deaths during day and night was performed through a nonparametric Chi squared test.

Finally, we identified factors that most influenced death of vertebrates on road: meteorological conditions, temperature and time of year - through Multiple Linear Regression.

A non-parametric Mann Whitney hypothesis test was carried out in order to verify if pre and post fire had significant differences between them.

Tests were performed with the help of SPSS Statistics 17.0 and graphics by Microsoft Excel.

\section{Results}

After using Mann Whitney's non-parametric test to compare two zones, there were significant differences in variables "Mammals" $(Z=-3.321, p<0.05)$, "Birds" $(Z=-2.248, p<0.05)$ and winter $(Z=-3.193, p$ $<0.05)$. In this way, forest area has a significantly higher number of mammalian deaths than agricultural area, as does the number of deaths associated with winter. On contrary, agricultural area showed a higher number of bird deaths than forest area, during spring / summer period, which was not supported by statistical analysis of Mann-Whitney test. After a fire, there is a significant difference of affected species and number of individuals killed in both zones.

Given these results, the two zones were analyzed separately.

Agricultural area.

During 15 months of study in agricultural area, 113 animals were collected from roads, $58 \%$ birds, $17 \%$ mammals, $6 \%$ reptiles and $19 \%$ amphibians (figure 3 ). Of 17 species found on agricultural roads, the two 
most abundant were common sparrow (Passer domesticus) and fire salamander (Salamandra salamandra), , representing, respectively, $15.9 \%$ and $8.8 \%$ of animals ran over.

There were more deaths during night $(n=12)$ than day $(n=8)$; however, after Chi-square adjustment test, these differences were not significant $(\chi 2=0.800, d f=1, p>0.05)$.

Mean monthly abundance of vehicle collisions was $6.50 \pm 3.55$, ranging from 2 to 14 animals. Thus, highest number of deaths occurred in autumn (32,7\%), with values higher than 10 individuals for poultry class (figure 4).

Birds were predominant group during study, being class most affected in months of July and September to December. Amphibians were most affected class in month of February and after fire, reptiles were most affected during spring and early summer and after fire while mammals had highest mortality in August and after fire. ANOVA allowed to test if average numbers of deaths of different taxonomic groups differed between seasons of year. Results showed that there are significant differences in number of bird deaths between spring and fall.

Mean mortality rate in this area was approximately 7.53 ind./ Km / year \pm 11 and two hotspots were found on agricultural roads, one on each road studied. On Road 5 (Rua da Fonte, in Ermida, which goes to Colmeal) a hotspot was registered in road segment ahead of Montalvo. Deaths in this segment account for $50 \%$ of deaths recorded on road and $78 \%$ of deaths on first transect. Most affected taxonomic group in this segment was birds $(n=8)$.

In Road 6 (Barra de Mira - Poço da Cruz), the hotspot was at northern terminus of transect, corresponding to $27 \%$ of total deaths of this road and $47 \%$ of deaths of second transect. Once again, birds were most affected with 8 individuals killed in this segment.

Multiple Linear Regression allowed to identify factors that most influence death of four taxonomic groups in agricultural roads, through the result obtained in Pearson correlation. Most important factor for death of amphibians was "seasons of year" ( $p=0.109)$, with highest number of deaths in autumn and winter. As for birds, "seasons of the year" $(p=0.254)$ appear to be the factor that most favored deaths of this group, with highest number of deaths on spring days. On the other hand, mammals have "temperature" as the most relevant factor in their death on roads $(p=0.236)$, with highest number of deaths on relatively hotter days. Finally, the most influential factor in reptile death $(p=0.448)$ is "weather conditions", with highest number of deaths occurring on rainy / cloudy days.

Non-parametric Mann Whitney hypothesis test showed significant differences before and after fire in agricultural zone $(Z=-2.446, p<0.05)$. After a fire there is an increase in number of amphibian deaths. Reptile deaths have risen slightly. Number of bird deaths has declined sharply. In mammal class there is an increase in number of deaths (figure 5).

Forest area. 
In forest area, 212 animals were found hit by vehicles on roads. Of these, 31\% are mammals, $19 \%$ birds, $12 \%$ reptiles, $38 \%$ amphibians (figure 6 ). Most affected species in this area were toad (Bufo bufo)," with $11.8 \%$ of total dead individuals, and fire salamander (Salamandra salamandra),, with $10.4 \%$.

After chi-square adjustment test, it was found that number of deaths occurred during day and at night was not significantly different $(\chi 2=0.118 ; d f=1 ; p>0.05)$, although there were recorded more deaths during night than during day.

Average monthly abundance of vehicle collisions was $14.13 \pm 5.52$, ranging from 1 to 29 animals (figure 7).

Classes most affected by fire were birds and mammals. ANOVA allowed us to test whether average number of deaths of different taxonomic groups differed between seasons. Results show that both amphibians and reptiles show differences between seasons: amphibians have a higher mortality during winter $(F=0.7666 ; d f=2 ; p<0.05)$ and reptiles a mortality higher in spring $(F=5.464, d f=2, p<0.05)$. Species richness ranged from one species in August to seven species in March.

Number of deaths was significantly different between two substrate types of roads (macadam and asphalt), and no animals were collected on macadam roads. Thus, total number of individuals counted in forest zone refers only to deaths on asphalt roads.

Mean mortality rate in this area was approximately 14.1 ind./Km / year \pm 17 and there were three hotspots on these roads: one on Road 1 and two on Road 3. Road 1 (roundabout from exit of A17 MiraNorte towards Poço da Cruz) recorded its hotspot approximately halfway along transect one, parallel to village of Cabeças Verdes. These deaths coincide with $50 \%$ of total accounted for on this road. The more reached taxonomic group were the reptiles.

In Road 3 (Praia de Mira - Ermida) there are two well-defined hotspots, both on first transect. Group 1 accounts for $18.50 \%$ of deaths in total length of road and $25.60 \%$ of transect. Group 2 , on the other hand, shows $37.00 \%$ of road deaths and $51.00 \%$ of deaths of first transect. Amphibians were group that presented the most deaths in both groups ( $n=8$, for Group 1 and $n=13$, for Group 2).

Multiple Linear Regression allowed to identify factors that most influence death of four taxonomic groups in agricultural roads, through the result obtained in Pearson correlation. Most important factor for death of amphibians in forest area was "seasons of the year" ( $p=0.494)$, with more deaths occurring during winter. For birds, "meteorological conditions" have highest correlation with mortality in this group $(p=0.381)$. "seasons of the year" are the most influential in mammalian death $(p=0.218)$, with more fatalities observed during winter. Finally, reptiles are more vulnerable to death on road on sunny days, as "weather conditions" are most conditioning factor $(p=0.194)$.

Non-parametric Mann Whitney hypothesis test showed significant differences before and after fire $(Z=-$ $0.295, p<0.05)$. After forest fire there was an absence of reptile and amphibian deaths. You can also see 
increase in bird deaths. There is also a large increase in number of mammalian deaths following fire on asphalt roads (figure 8 ).

On macadam roads there is a continuation of non-existence of deaths.

\section{Discussion}

In agricultural area, 113 animals were collected from the roads, being $58 \%$ birds, $19 \%$ amphibians, $17 \%$ mammals and $6 \%$ reptiles. These results are in line with other works carried out in Portugal: in IP2, in S. Manços, EN4, in Vendas Novas (Ascenção, 2001) and in EN 118, in Tejo Estuary (Marques, 1994). Of the 20 species found, most abundant was common sparrow (Passer domesticus).. These results agree with Erritzoe et al. (2003), who report that, in Western Europe, sparrows are species that most often die on roads. Percentage of deaths associated with common sparrow may be due to behavioral and eating habits of this species. Common sparrow inhabits zones with human activity and is commonly found in agricultural areas feeding on cereals (Erritzoe et al.,n2003), two characteristics present in the study area. As on two monitored roads, generally houses were on opposite side of farmland relative to road, birds tended to cross road, increasing probability of collision. In addition, sparrows not only have large populations, but are also not shy and tend to react less when a vehicle emerges (Heinrich, 1978).

It is worth noting collection of half of a Eurasian eagle-owl (Bubo bubo) in Road 6 (Barra de Mira-Poço da Cruz). According to Petronilho (2001), only record of this species in Mira county was made on October 26, 1999, in Barra de Mira. In Portugal, this species is considered rare. Threat factors are related to loss of favorable habitat, illegal hunting and disturbance in nesting sites. Thus, it would be important to verify presence of a possible population in place. A specimen of common waxbill, Estrilda astrild, was also collected on same road. This bird inhabits agricultural fields with cereal cultivation (corn fields) and according to Petronilho (2001), is a nesting and wintering resident uncommon in the county. An individual of this species was found on Praia de Mira, on November 5, 1995, about a month after being ringed in the Paúl de Madriz. As this species is also bred in captivity, the individual found may have escaped captivity or belong to resident population of county.

Although number of vertebrate deaths recorded during day and night was not significantly different $(\chi 2=$ $0.800 ; d f=1 ; p>0.05)$, there was a higher number of deaths during night, being birds and reptiles the most affected. Birds result contradicts most of literature found. In former German Democratic Republic (Lüpke, 1983), most birds were killed in early hours of day. In Sweden, peak occurred at 7 a.m. and 5 p.m., mostly at mornings, and Saturday and Sunday at noon (Göransson et al.,, 1978). However, there is a record in New England that defines most fatalities at dusk between 3:30 p.m. and 09 p.m. (Zumeta and Holmes, 1978).

On the other hand, about reptiles there is literature that supports result of present work. Reptiles being ectothermic require heat from outside and, at night, they may find it on roads surface. This event, associated with slow reptile mobility, causes a higher vulnerability of this group to trampling (Shine et al.,, 2004). 
Most deaths occurred in spring, early summer and autumn (57.5\%) and birds were most affected class during this time. In fact, two seasons of year are related to life cycle of birds, coinciding with their breeding season. In addition, this season is rich in cereals on agricultural land adjacent to road, providing them with enough food for whole season. In the same way, vehicular traffic increased in June, July and August due to summer vacations and movement on beaches. These data are supported by literature (Erritzoe et al.,, 2003). These values may be due to local scavengers (Hels and Buchwald, 2001). For example, during study several birds and reptiles were observed feeding ants. At the same time, several birds of prey (for example, Buteo buteo and Falco tinnunculus) as well as crows (Corvus corax) were observed.

The hotspots identified on agricultural roads revealed more bird deaths. This can be justified by the amount of food present in fields adjacent to the road. In addition, the segment with the highest mortality on Road 6 is closer to the trench that runs almost parallel to the road, which can demonstrate the effect of the road as a barrier to the movement of animals moving to drink. Road 5, on the other hand, had a hotspot in front of Montalvo, a place with little slope and wide-open fields and with food. The identification of these points can be crucial in management of study place biodiversity, allowing installation of mitigation measures in areas with higher mortality.

Mortality of amphibians in agricultural zone is associated with winter and rainy days. In fact, considering that humidity is a determining agent in life cycle of amphibian and breeding season occurs in autumn, winter and spring (Oliveira and Crespo, 1989), the probability of being hit during this period and on rainy days is higher.

Mortality of birds on agricultural roads is influenced by seasons and weather conditions. Birds have their greatest activity on sunny days. Spring corresponds to breeding season of birds (Erritzoe et al..,2003). These two factors lead to greater mobility of birds that, when crossing roads, are vulnerable to vehicle collisions.

On the other hand, mammalian deaths in agricultural area were more closely related to temperature followed by seasons, with relatively warm temperatures being most favorable to collisions. This result agrees with a study by Smith Patten and Patten (2008) that most of mammalian deaths occurred in spring.

Susceptibility of reptiles to agricultural roads proved to be higher during rainy / cloudy days. These results contradict previous literature (Forman et al.,, 2003, Kline and Swann, 1998, Rosen and Lowe, 1994), who report that reptile deaths are associated with hot and sunny days. However, there is a possible explanation for results obtained. In period in which this study was carried out, seasons were poorly defined, with spring and autumn being hot and dry seasons and there were a few days of rain in August. These factors may have affected results, since amphibians appeared during August and reptile deaths were related to rainy days. In fact, most of reptile's collections occurred early in morning which meant they had died the night before. The days before gatherings coincided with sunny days. Thus, probably, reptiles at time of their death would be warming themselves on roads with heat released by them. 
After fire, birds were no longer seen dead, which indicates that many were killed by fire that arrived in this area already during night which prevented birds to flee in a timely manner. There have been more mammalian deaths and probably due to the fact that they are looking for food in more distant areas, which increases risk of collision. Number of dead amphibians has decreased, probably due to fact that the fire has lost its intensity and because there are small puddles of land irrigation that allowed animals of this class to escape fire.

In forest area, 212 animals were found hit by vehicles on roads. Of these, $31 \%$ are mammals, $19 \%$ birds, $12 \%$ reptiles, $38 \%$ amphibians. These results are not in agreement with other studies conducted in Mira, Portugal and Orense, Spain (Petronilho and Dias, 2005), where amphibians were the most affected by the mortality rate above $80.00 \%$. This result, diverted from other similar studies, is due to the fact that after fire, a large percentage of mammals die.

Species most threatened by road in this area were common toad (Bufo bufo)," with $11.8 \%$ of total dead individuals, and fire salamander (Salamandra salamandra),, with $10.4 \%$. Again, these data agree with works of Petronilho and Dias (2005). In first study, Bufo bufo was species that presented highest value of mortality (49\%) and Salamandra salamandra also recorded high mortality. However, in present study, Bufo bufo mortality value was lower. This may be due to lower monthly frequency of collections: in this work collections were carried out biweekly, while in study by Petronilho and Dias (2005), 10 monthly collections were made and by the fact that after fire no amphibians were found dead. Similarly, one of roads monitored in 2005 study was asphalted again, which generally implies higher mortality values in original vertebrate populations due to first impact. González-Prieto et al. (1993) reported a mortality of Bufo bufo of $10.00 \%$ and of Salamandra salamandra 3.10\%. The level of rainfall, vegetation cover and ditches in lands adjacent to roads could have been strong determinants for number of deaths obtained. In fact, humidity is a relevant factor in life cycles of amphibians and it is important to note that reproduction period of this group occurs in winter, summer and spring (Oliveira and Crespo, 1989). In addition, vegetation cover provides places of refugee. If breeding sites are on opposite side of road, amphibians will be forced to cross it, increasing the likelihood of colliding with vehicles.

Although number of deaths during day and at night was not significantly different $(X 2=0.118 ; d f=1 ; p>$ $0.05)$, more deaths occurred at night. This may be due to lesser visibility of driver and animal as well as behavior of animal. For example, mortality of amphibians was higher at night, which may be justified by their nocturnal activity (Almeida et al.,, 2001).

In general, monthly distribution of vertebrates killed by vehicle collision in forest zone tends to decrease from January to September and increase again after fire. It should be noted that these results are opposite to those of the agricultural zone whose monthly distribution increases over study period. Most of deaths in forest area occurred, therefore, in winter and after fire and amphibians were most affected group before fire, giving place to mammals after fire. The winter is defined by rainfall and cold and humid days that provide excellent conditions for amphibians (Oliveira and Crespo, 1989). ANOVA performed in this zone showed that number of deaths of amphibians and reptiles differed between seasons. 
Amphibians were most affected during winter for reasons previously mentioned. Reptiles exhibited higher mortality during spring and autumn 2016 for it was a dry and hot autumn on the usual paw season.

Petronilho and Dias (2005) presented similar results, with a higher number of individuals killed at the end of spring. Oliveira and Crespo (1989) stated that April and June were the months when Montpellier snake (Malpolon monspessulanus) had higher rates of activity because of reproduction. Sun exposure of reptiles and their difficulty in locomotion on asphalt roads may also determine their mortality during spring.

Number of deaths on both types of road substrate (macadam and asphalt) was significantly different. In fact, no animals were counted on macadam roads, showing the importance of substrate type for vertebrate road deaths. The justification for these remarkable results is volume and speed of traffic in each type of road (Forman et al.,, 2003). In studied macadam roads, cars rarely passed, due to degradation and substrate holes (van Langevelde and Jaarsma, 2004).

Mean mortality rate in this area was approximately $14.1 \mathrm{ind} . / \mathrm{Km} /$ year \pm 17 .

These values are much lower than those of González-Prieto et al. (1993) (639.5 ind./Km / year). This disparity may be due to volume and speed of traffic on roads of different studies (González-Prieto et al. (1993) studied a national road) and to the local scavengers (Hels and Buchwald, 2001).

Three hotspots were observed on forest roads. On Road 1, segment with highest mortality is located near a curve, which may have contributed to poor visibility of drivers, and at a road junction, which increases asphalt surface heated for reptiles (group most affected in this segment). Vegetation in this place is dense, contrary to majority of transect 2 constituted by scrub. Road 3, of all roads with highest mortality, revealed two hotspots. Both are located in flatter parts and without near slopes of road what facilitates enough movement of amphibians, group more threatened in these segments. Additionally, both are located near ditches and have dense vegetation cover with acacia, maritime pine, umbrella pine and many herbaceous. The site of Group 2 also has alders and reed along ditch, making this area wet and with plenty of shade. According to a study carried out by Eigenbrod et al. (2008), two species of amphibians (Pseudacris crucifer and Rana sylvatica) showed stronger associations with forest cover than with traffic, preferring denser forest cover. Likewise, other studies corroborate results demonstrating importance of water, forest and urban areas as habitat variables that better predict amphibian mortality as well as relevance of vegetation that provides shade, moderates temperature, retains moisture and contributes to organic matter (Glista, 2007, Herrmann et al.., 2005).

Amphibian mortality in forest zone is associated with winter and lower temperatures. Curiously, it seems that in this zone temperature is a more relevant factor in death of amphibians than meteorological conditions.

Mortality of birds on forest roads is influenced by sunny days and high temperatures and by vegetal cover. In fact, birds have higher activity on sunny days, overpasses and crossing roads, and high 
temperatures are usually related to the end of spring and summer, coinciding with breeding season (Erritzoe et al.., 2003). Thus, probability of collision of birds with vehicles increases.

Mammals appear associated with winter and lower temperatures, both related. This may be due to poor visibility of driver and animal on rainy days. Oddly, weather conditions do not appear as the most determining factor in deaths in this group. However, these results do not agree with data from Smith Patten and Patten (2008) who report that most mammalian deaths occurred in spring.

Finally, reptiles are more vulnerable to death on road on sunny days and relatively warm. These results agree with Kline and Swann (1998) and Rosen and Lowe (1994). Reptiles approach roads to warm themselves on their surface, which in turn is warmed by sun and, consequently, reptiles become more susceptible to run over.

With fire, vegetal cover disappeared along with a great part of animals. There was an increase in number of mammals killed on asphalt roads, since after fire they were forced to look for food in more distant areas and to move to small spots of forest that did not burn. There was also an absence of deaths of reptiles and amphibians on road probably because once they were not fast animals, they could not escape fire and died during fire. On macadam roads there is a continuation of non-existence of deaths because speed at which vehicles move in these transects is so small that animals can escape in a timely manner.

\section{Conclusion}

Roads can affect quality and quantity of wildlife habitat available, mostly through fragmentation. As well, vehicular traffic on roads can be a direct source of mortality for wildlife, and in some cases can be catastrophic for populations. Thus, habitat connectivity and permeability of road systems are important factors to consider when developing roadway mitigation systems (Glista et al.,, 2007).

In this study, it was concluded that different zones and therefore different habitats should be worked on separately and that mitigation measures should be implemented as a priority in so-called "hotspots" of roads. Thus, hotspots detected on agricultural roads suggest mitigation measures especially for birds, for example, by placing belts of tall trees slightly distant $(>3 \mathrm{~m})$ at some distance from edge of road, in order to force birds to flying higher and thus avoiding collision (Erritzoe et al.,, 2003). With regard to measures that could be implemented on forest roads, these would be especially directed to amphibians, with construction of galleries in tube $(0.32 \mathrm{~m}$ in diameter) with natural substrate inside structure and with grid tops in order to humidity of gallery. In addition to galleries, fences would be placed that would lead animals to passages (Glista et al.,, 2007).

This work highlights importance of secondary roads as a source of mortality for wildlife, and these should not be ignored. As far as macadam roads are concerned, they are not a threat to vertebrate populations in municipality of Mira. 
In future, it would be important to improve this work by including volume of traffic on roads and recording kilometers at which animals were collected.

Results before and after fire illustrate the impact of this catastrophic event on wildlife. Impacts should be interpreted for different coexistence, niches and links between ecosystem functions and their underlying biological processes for present floristic and faunistic ecosystem components. In this such catastrophic fire (dimension and intensity) impacts seems to be negative for some faunistic components (taxonomies). Long term monitoring of system is going to be maintained for recovering phase and stabilization.

\section{Declarations}

\section{Ethics approval and consent to participate}

There was no requirement to seek ethical approval to carry out the work described above.

\section{Consent for publication}

Not applicable.

\section{Availability of data and materials}

The datasets used and/or analysed during the current study are available from the corresponding author on reasonable request.

\section{Competing interests}

The authors declare that they have no competing interests.

\section{Funding}

Not applicable

\section{Authors' contributions}

The lead author collected the data and wrote the article, the co-authors read, improved, and approved the article for publication. 


\section{Authors' information}

For professional reasons the authors prefer not to give their information.

\section{Acknowledgements}

Not applicable

\section{References}

Almeida, N. F., Almeida, P. F., Gonçalves, H., Sequeira, F., Teixeira, J., Almeida, F. F., 2001. Guia FAPAS Amphibians and Reptiles of Portugal. 1st Edition, FAPAS. Port.

Ascenção F., 2001. Mortality of vertebrates due to run-over in IP2 (Portalegre-Monforte and S. MançosPortel sections) and EN4 (Vendas Novas-Montemor section). In: Vertebrate mortality due to road accidents in Alto Alentejo. Report of internship to obtain the Degree in Applied Animal Biology - Terrestrial Variant. Faculty of Sciences of the University of Lisbon: 3-16.

Butler Bret W., 2010. Tree injury and mortality in fires: developing process-based models. Fire Ecology Volume 6, Issue 1.

Clarke, G. P., White, P. C. L., Harris, S., 1998. Effects of roads on badger Meles meles populations in southwest England. Biological Conservation 86: 117-124.

Crotteau Justin S., J. Morgan Varner III, Martin W. Ritchie, 2013. Post-fire regeneration across a fire severity gradient in the southern Cascades. Forest Ecology and Management, volume 287, Pages 103112. https://doi.org/10.1016/j.foreco.2012.09.022

Dickinson, Matthew B., 2010. Introduction: Strengthening the foundation of wildland fire effects prediction for research and management. Fire Ecology Volume 6, Issue 1.

Eigenbrod, F., Hecnar, S. J. and Fahrig, L., 2008. The relative effects of road traffic and forest cover on anuran populations. Biological Conservation, 141: 35-46.

Engstrom, R. T. 2010. First-order fire effects on animals: review and recommendations. Fire Ecology 6(1): 115-130.

Erritzoe, J., Mazgajski, T. D. and Rej, Ł, 2003. Bird casualties on European roads - a review. Acta Ornithologica, 38: 77-93.

Forman, R. T. T., 1995. Land mosaics: the ecology of landscapes and regions. Cambridge University Press, Cambridge, UK. 
Forman, R. T., Alexander, L. E., 1998. Roads and their major ecological effects. Annual Review of Ecology Evolution and Systematics, 29: 207-231.

Forman, RTT, Sperling, D., Bissonette, JA, Clevenger, A., Cutshall, C., Dale, V., Fahrig, L., France, R., Goldman, C., Heanue, K., Jones, J., Swanson, F., Turrentine, T., Winter, T. (2003). Road Ecology: Science and Solutions. Island Press, Washington.

Gerlach, G. and Musolf, K., 2000. Fragmentation of landscape as a result of genetic subdivision in blank voles. Conservation Biology, 14: 1066-1074.

Glista, D. J., DeVault, T. L. and DeWoody, J. A., 2007. Vertebrate road mortality predominantly impacts amphibians. Herpetological Conservation and Biology, 3 (1): 77-87.

Goosem, M., 1997. Internal fragmentation: the effects of roads, highways, and powerline clearings on the movements and mortality of rainforest vertebrates. In Tropical Forest Remnants, Ecology, Management, and Conservation of Fragmented Communities (Laurance, W. F. and Bierregaard, R. O., eds., Pp. 241-255, University of Chicago Press.

Gonzalez-Prieto S, Villarino A, Freán M (1993) Mortalidade de vertebrados por atropello en una carretera nacional del NO de Espana. Ecologia 7: 375-389.

Göransson G., Karlsson J., Lindgren A., 1978. [Influence of roads on the surrounding nature. II. Fauna]. Rapport från Statens Naturvårdsverk.

Groot Bruinderink, G. W. T. A., Hazebroek, E., 1996. Ungulate traffic collisions in Europe. Conservation Biology, 10: 1059-1067.

Harper Craig A., 2016. Fire effects on wildlife in the central hardwoods and appalachian regions, USA. Fire Ecology Volume 12, Issue 2.

Haxton, T., 2000. Road mortality of snapping turtles, Chelydra serpentine, in central Ontario during their nesting period. Canadian Field-Naturalist, 114: 106-110.

Heinrich D., 1978. Untersuchungen zur Verkehrsopferrate bei Säugetieren und Vögeln. Die Heimat, 85: 193-208.

Hels, T., Buchwald, E., 2001. The effect of road kills on amphibian populations. Biological Conservation, 99: $331-340$.

Herrmann, H. L., Babbitt, K. J., Baber, M. J. and Congalton, R. G., 2005. Effects of landscape characteristics on amphibian distribution in a forest-dominated landscape. Biological Conservation, 123: 139-149. 
Hutto, R. L. (2008), THE ECOLOGICAL IMPORTANCE OF SEVERE WILDFIRES: SOME LIKE IT HOT. Ecological Applications, 18: 1827-1834. doi:10.1890/08-0895.1

Jonsen, I. D. and Taylor, P. D., 2000. Fine-scale movement behaviors of calopterygid damselflies are influenced by landscape structure: an experimental manipulation. Oikos, 88: 553-562.

Jornal de Noticias. 2017. Mira denuncia falha no SIRESP. October $17^{\text {th }}$. https://www.jn.pt/local/noticias/coimbra/mira/interior/mira-denuncia-falha-no-siresp-8851819.html

Joyce, T. L. and Mahoney, S. P., 2001. Spatial and temporal distributions of moose-vehicle collisions in Newfoundland. Wildlife Society Bulletin, 29: 281-291.

Kline, N. C. and Swann, D. E., 1998. Quantifying wildlife road mortality in Saguaro National Park. In Proceedings of the International Conference on Wildlife Ecology and Transportation, edited by G. L. Elvink, P. Garrett, D. Zeigler and J. Berry, 23-31. Publication FL-ER-69-98. Tallahassee: Florida Department of Transportation.

Lankester, K., Van Apeldoorn, R., Meelis, E., Verboom, J., 1991. Management perspectives for populations of the Eurasian badger (Meles meles) in a fragmented landscape. Journal of Applied Ecology, 28: 561573.

Laurance, S. W., Stouffer, P. C. and Laurance, W. F., 2004. Effects of road clearing on movement patterns of understory rainforest birds in Central Amazonia. Conservation Biology, 18: 1099-1109.

Laurance, S. G., 2004. Responses of understory rain forest birds to road edges in central Amazonia. Ecological Applications, 14: 1344-1357.

Laurance, W. F., Albernaz, A. K. M., Schroth, G., Fearnside, P.M., Bergen, S., Venticinque, E. M., Costa, C., 2002. Predictors of deforestation in the Brazilian Amazon. Journal of Biogeography, 29: 737-748.

Laurance, W. F., Croes, B. M., Guissouegou, N., Buij, R., Dethier, M. and Alonso, A., 2008. Impacts of roads, hunting, and habitat alteration on nocturnal mammals in African rainforests. Conservation Biology, 22: $721-732$.

Laurance, W. F., Croes, B. M., Tchignoumba, L., Lahm, S. A., Alonso, A., Lee, M. E., Campbell, P. and Ondzeano, C., 2006. Impacts of roads and hunting on central African rainforest mammals. Conservation Biology, 20: 1251-1261.

Liu, SL, Cui, BS, Dong, SK, Yang ZF, Yang, M., Holt, K., 2008. Evaluating the influence of road networks on landscape and regional ecological risk - A case study in Lancang River Valley of Southwest China. Ecological Engineering, 34: 91-99.

Lüpke M., 1983. Vogelverluste an einer Fernverkehrsstrasse. Falke, 30: 58-60. 
MacDonald, D., Barret, P., 2002. FAPAS Guides Mammals of Portugal and Europe. 1st Edition, FAPAS. Port.

Marques, J. M. 1994. Vertebrates killed by trampling - E. N. 118. (Roadkills in The E. N. 118). Seminar on the evaluation of the Environmental Impact of road projects. Thorn.

Meunier, F. D., C. Verheyden, and P. Jouventim, 2000. Use of roadsides by diurnal raptors in agricultural landscapes. Biological Conservation, 92: 291-298.

Novelli, R., Takase, E. and Castro, V., 1988. Study of birds killed by collisions with vehicles in a stretch of Highway BR-471, between Quinta and Taim, Rio Grande do Sul, Brazil. Brazilian Journal of Zoology, 5: 441-454.

Observador. 2017. 2017 será o pior ano em área ardida. Sistema europeu aponta para mais de 500 mil hectares. October $18^{\text {th }}$. http://observador.pt/2017/10/18/2017-tera-sido-o-pior-ano-em-area-ardidasistema-europeu-aponta-para-mais-de-500-mil-hectares/.

Oliveira, M. E. and Crespo, E. G., 1989. Atlas of the distribution of Amphibians and Reptiles of Continental Portugal. S. N. P. R. C. N. Lisbon.

Peres, C. A. and Lake, I. R., 2003. Extent of nontimber resource extraction in tropical forests: accessibility to game vertebrates by hunters in the Amazon Basin. Conservation Biology, 17: 521-535.

Perry David A., Paul F. Hessburg, Carl N. Skinner, Thomas A. Spies. Scott L. Stephens, Alan Henry Taylor, Jerry F. Franklin, Brenda Mc Comb, Greg Riegel, 2011. The ecology of mixed severity fire regimes in Washington, Oregon, and Northern California.

Petronilho, J. M. S., Dias, C. M. M., 2005. Impact of two forest roads on wildlife after a road pavement changes in a coastal area in the center of Portugal. Wildlife Biology in Practice, 1: 128-139.

Petronilho, J., (2001). The Fauna of the Municipality of Mira. City Hall of Mira. Look. Pp. 15-21.

Philcox, C. K., Grogan, A. L., MacDonald, D. W., 1999. Patterns of otter Lutra lutra road mortality in Britain. Journal of Applied Ecology, 36: 748-762.

Pope, S. E., Fahrig, L. and Merriam, H. G., 2000. Landscape complementation and metapopulation effects on leopard frog populations. Ecology, 81: 2498-2508.

Quintana, S. M., Ramos, B. M., Martínez, M. Á. C., Pastor, I. O., 2010. A model for assessing habitat fragmentation caused by new infrastructures in extensive territories - Evaluation of the impact of the Spanish strategic infrastructure and transport plan. Journal of Environmental Management, 91: 10871096.

Rosen, P. C. and Lowe, C. H., 1994. Highway mortality of snakes in the Sonoran Desert of southern Arizona. Biological Conservation, 68: 143-148. 
Shine, R., Lemaster, M., Wall, M., Langkilde, T. and Mason, R., 2004. Report - Why did the snake cross the road? Effects of roads on movement and location of mates by Garter Snakes (Thamnophis sirtalis parietalis). Ecology and Society, 9: 9.

Smith-Patten, B. D. and Patten, M. A., 2008. Diversity, seasonality, and context of mammalian roadkills in the Southern Great Plains. Environmental Management, 41: 844-852.

Turner Monica G., Romme William H. Gardner Robert H. (1999) Prefire heterogeneity, fire severity, and early postfire plant reestablishment in subalpine forests of Yellowstone National Park, Wyoming. International Journal of Wildland Fire 9, 21-36. https://doi.org/10.1071/WF99003

Van Langevelde, F. and Jaarsma, C. F., 2004. Using traffic flow theory to model traffic mortality in mammals. Landscape Ecology, 19: 895-907.

Vijayakumar, S. P., Vasudevan, K. and Ishwar, N. M., 2001. Herpetofaunal mortality on roads in the Anamalai Hills, southern Western Ghats. Hamadryad, 26: 265-272.

Woodroffe, R. and Ginsberg, J. R., 1998. Edge effects and the extinction of populations within protected areas. Science, 280: 2126-2128.

Young, K. R., 1994. Roads and the environmental degradation of tropical montane forests. Conservation Biology, 8: 972-976.

Zumeta C., David \& T. Holmes, Richard. (1978). Habitat shift and roadside mortality of Scarlet Tanagers during a cold wet New England spring.

\section{Figures}

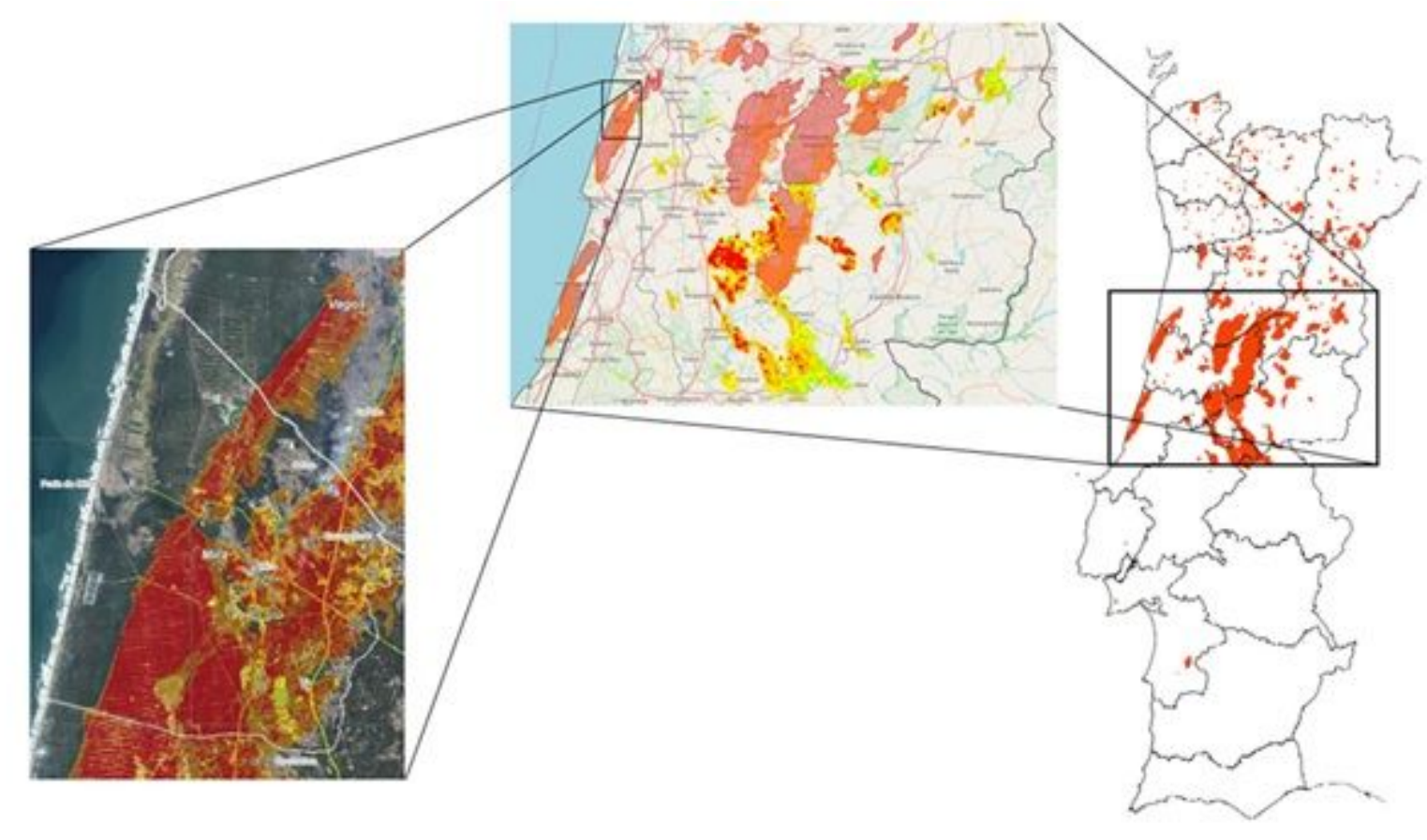


Figure 1

2017 Portugal and county of Mira burned area; Source: observador.pt and Program Copernicus, European Union.

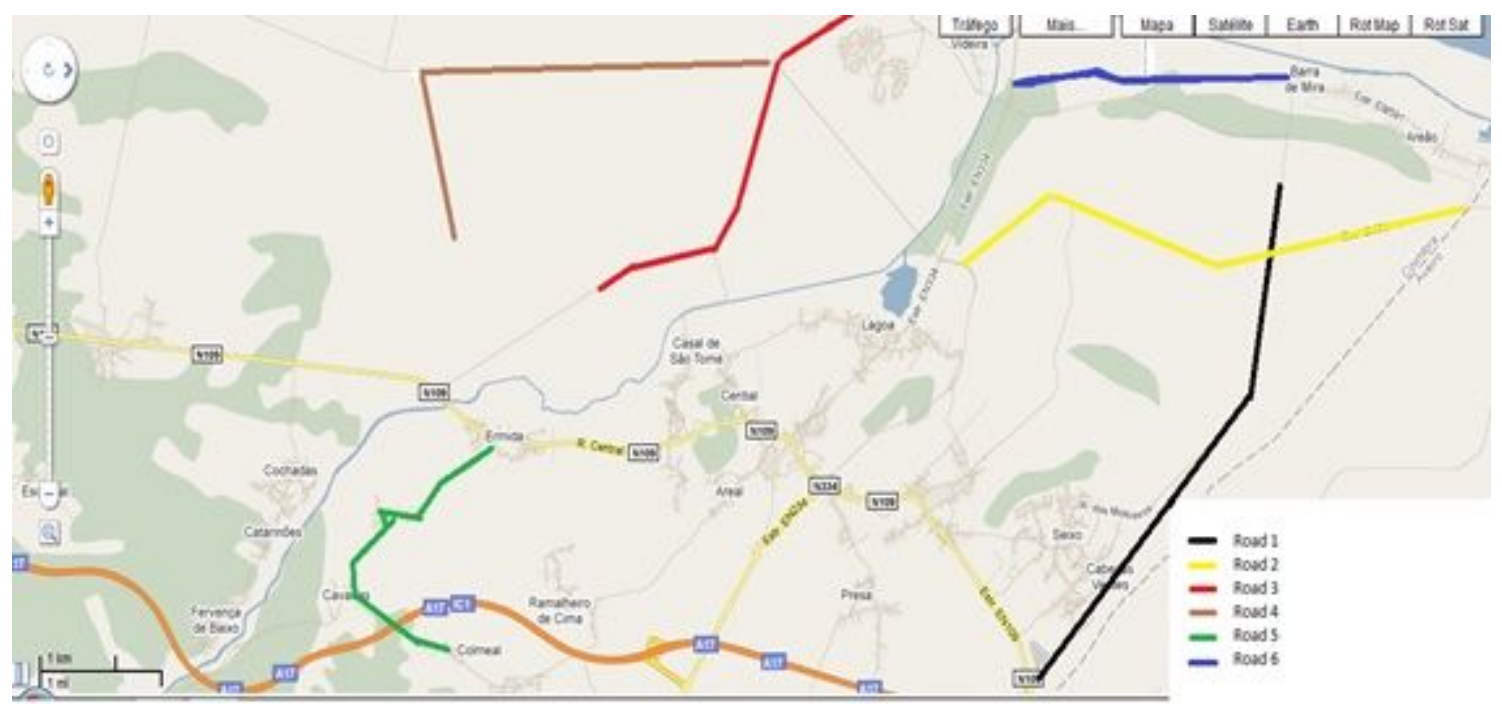

Figure 2

Roads studied: 1, 2, 3 and 4 - forest area; 5 and 6 - agricultural area; source Google Maps.

Agricultural zone

Deaths by classe

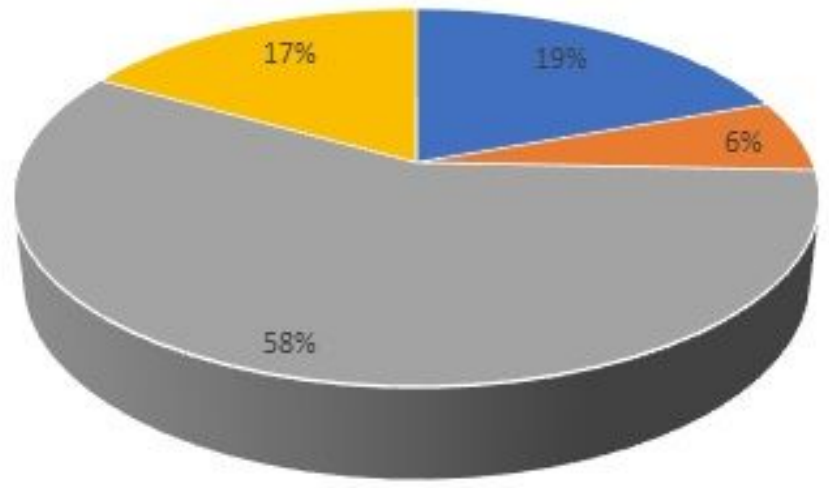

- Amphibians

- Reptiles

- Birds

- Mammals

\section{Figure 3}

Deaths on road by taxonomic group in agricultural area. 


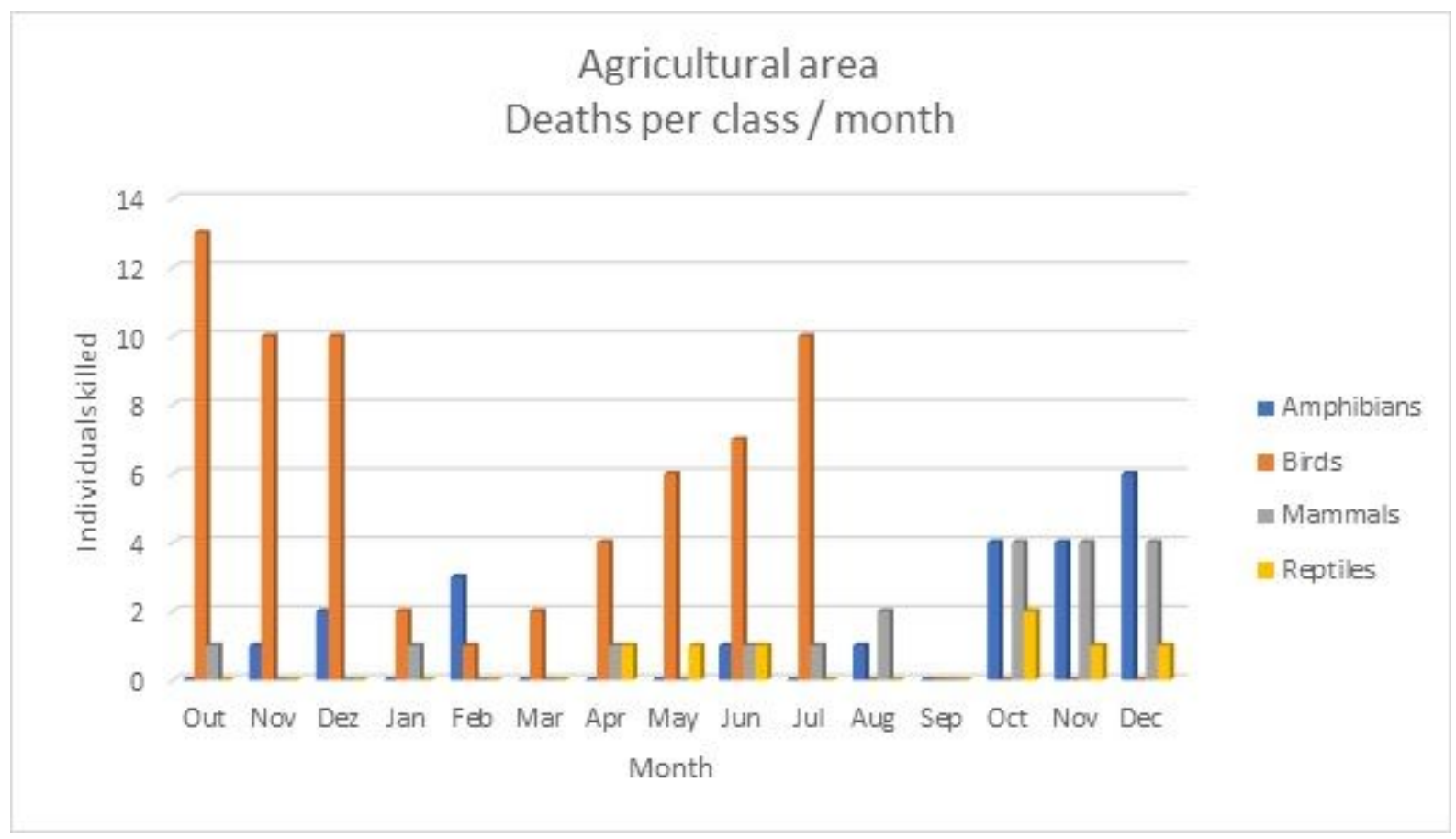

\section{Figure 4}

Monthly distribution of vertebrates killed by vehicle collision in agricultural zone

\section{Agricultural zone}

Comparison of post-fire with the same period of the previous year

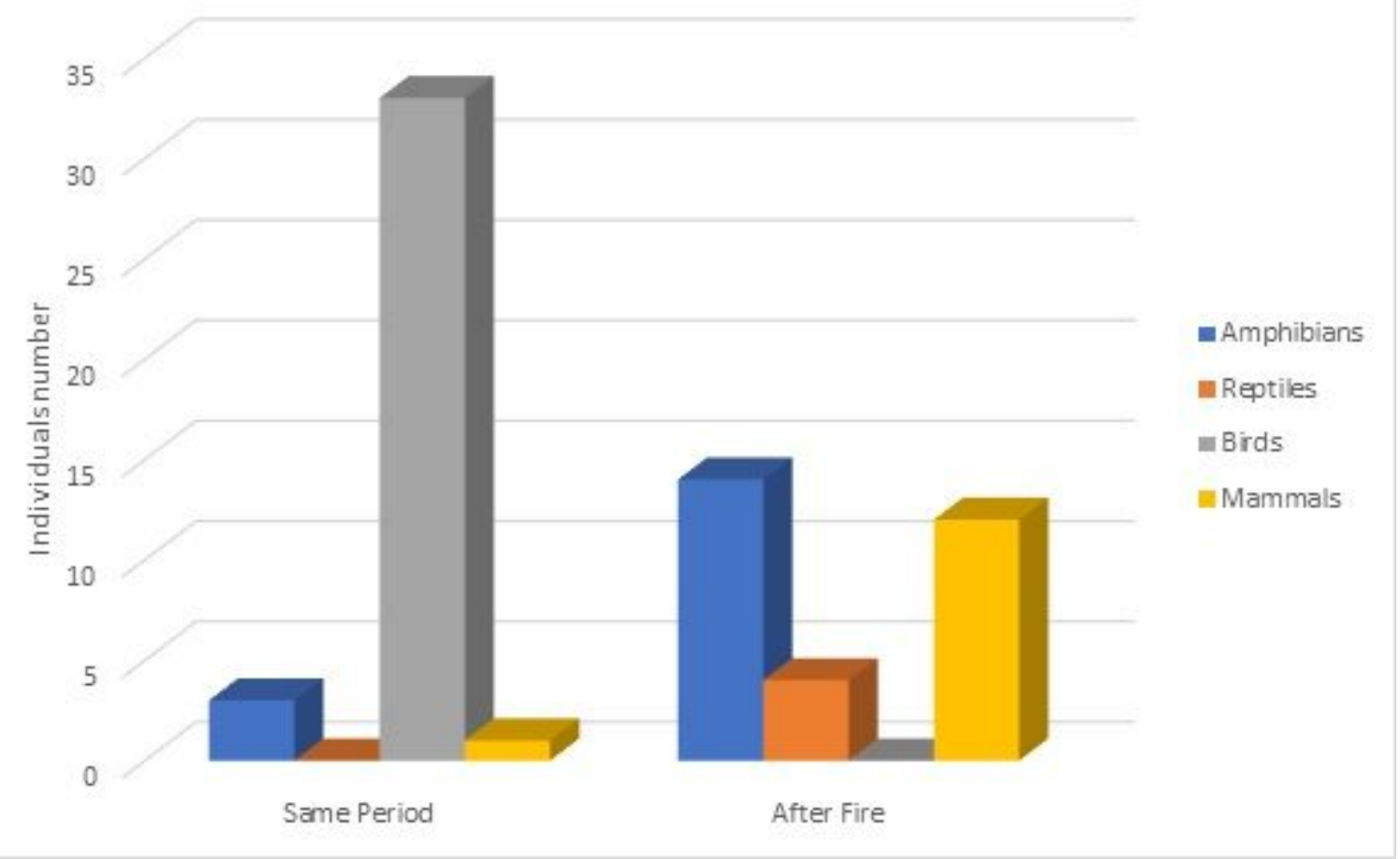

Figure 5

Comparison of deaths per classes pre and post fire 


\section{Forest zone}

Deaths by classe

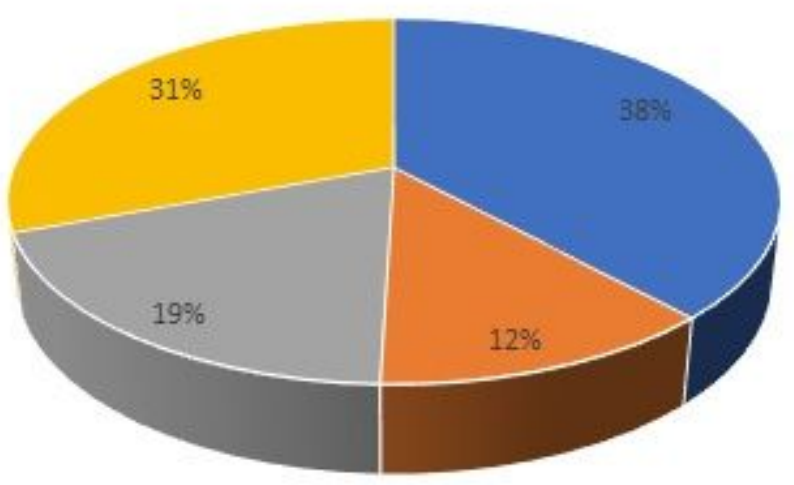

- Amphibians

- Reptiles

- Birds

- Mammals

\section{Figure 6}

Deaths on road by taxonomic group in forest zone.

Forest zone

Deaths per class / month

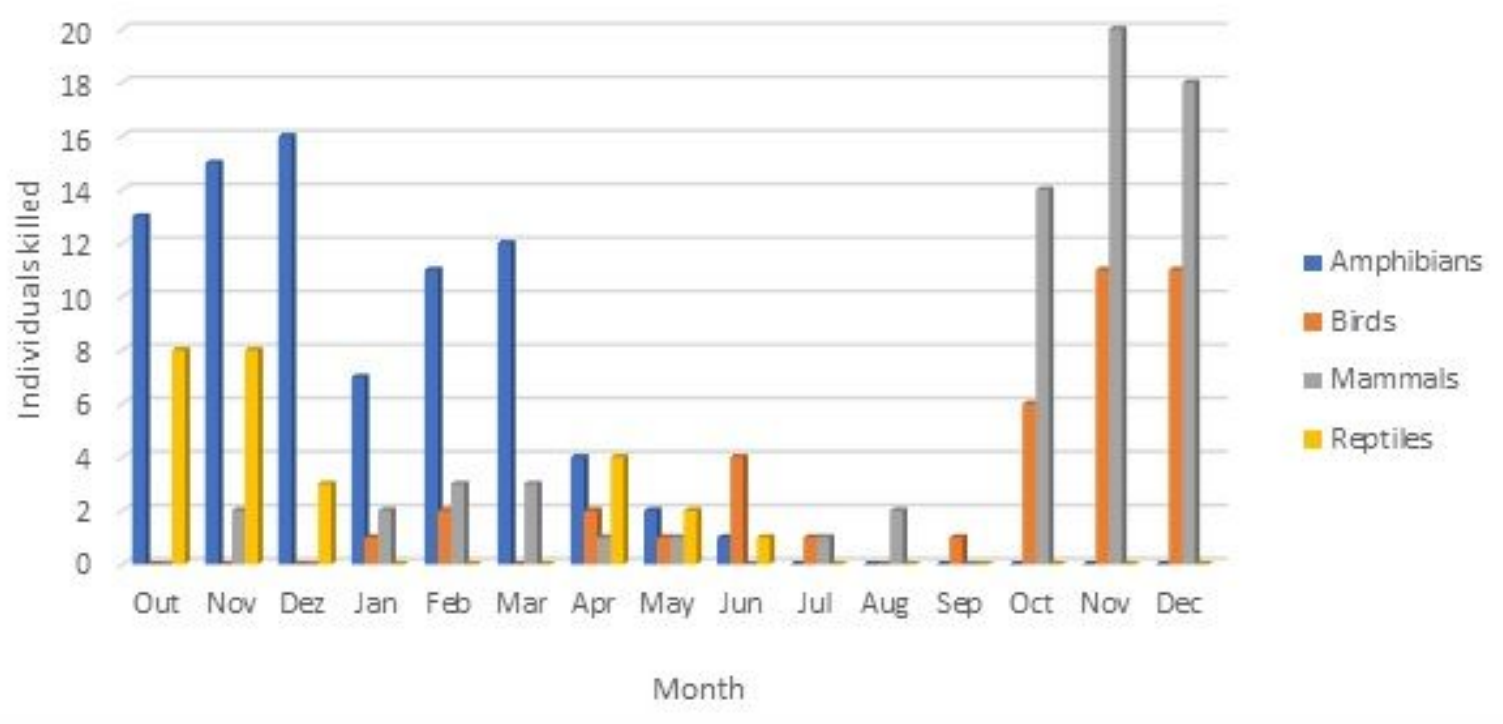

\section{Figure 7}

Monthly distribution of vertebrates killed by vehicle collision, in forest area. 


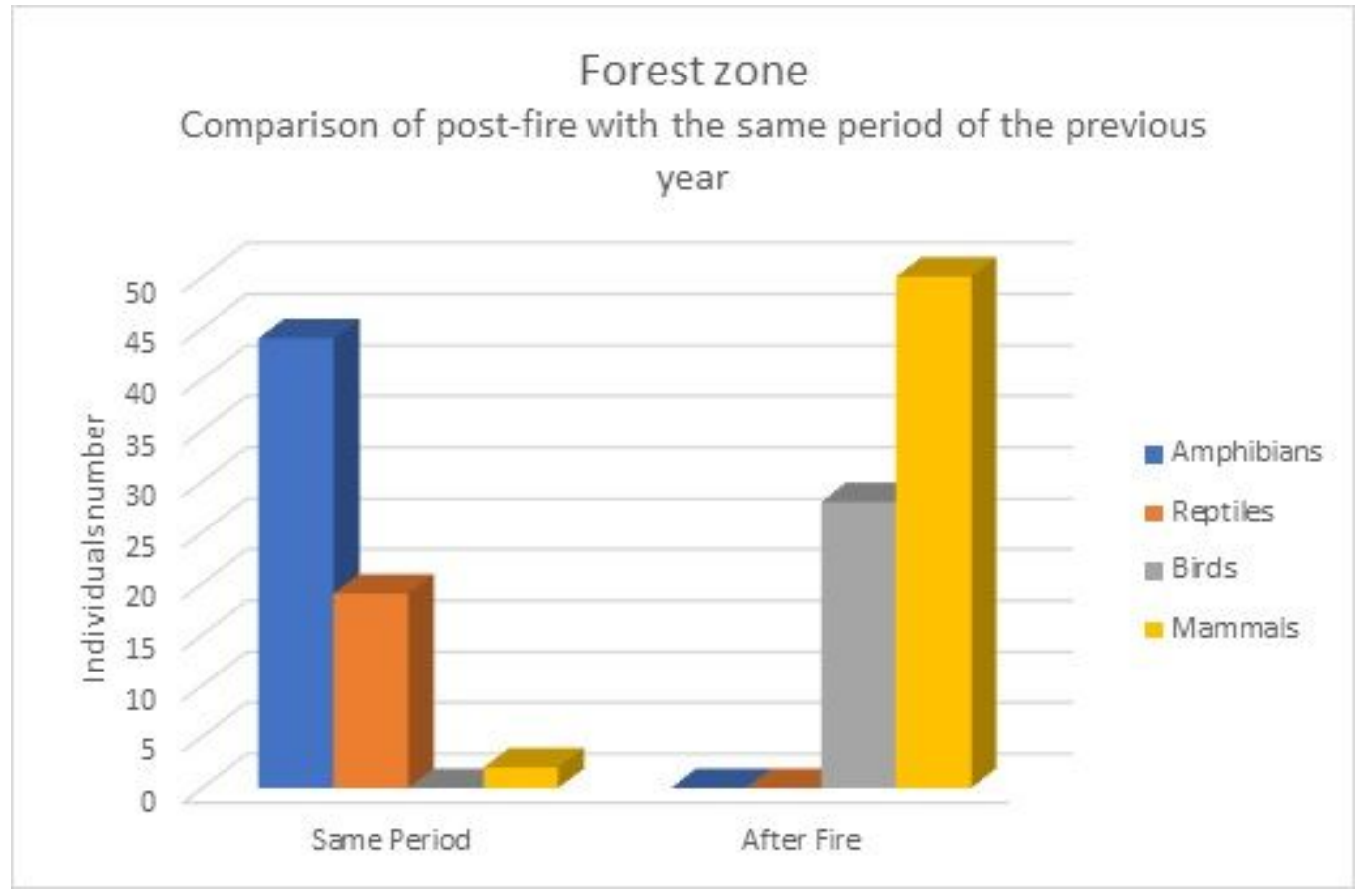

Figure 8

Comparison of deaths per classes by pre and post fire. 